\title{
The Timing of Elective Caesarean Deliveries and Early Neonatal Respiratory Morbidity in Term Neonates
}

\author{
Asmaa G.Tahir* \\ Manal B. Baythoon* \\ Yasir I. AL Saddi*
}

\author{
MBChB \\ CABP \\ FIBMS, DCH
}

Fac Med Baghdad 2018; Vol.60, No.1 Received: Dec. 2017 Accepted: Mar., 2018
Background: Respiratory distress is one of interesting presentation of elective caesarean delivery, the presence of labor before elective caesarean delivery decrease the risk of Respiratory distress. adverse respiratory problem in neonate delivered before 39 weeks of gestation are increased.

Objective: To evaluate the association between gestational age at delivery and neonatal respiratory outcomes after elective caesarean delivery between 37 and 41 completed weeks.

Patients and Methods: Descriptive study with prospectively collected data from Baghdad teaching hospital/Medical city at neonatal care unit. All infants of gestational age from 37 to 41 completed weeks, with uncomplicated pregnancy, of which 1407 were born by elective caesarean delivery compared to 1304, delivered by spontaneous vaginal delivery between 1st of September 2015 and 31st of January 2016. The neonates delivered by elective caesarean delivery were stratified into five groups according to the gestational age.

Result: There were 1407 neonates delivered by elective caesarean delivery compared with 1304 by spontaneous vaginal delivary of overall 118 neonates were admitted to the Neonatal care unit with Respiratory distress and receiving oxygen therapy or assisted ventilation. Early neonatal Respiratory distress risk was significantly higher in neonate delivered by elective caesarean delivery the rate of Respiratory distress increased with earlier gestational age for both group. The hospitalization days, also decreased with increased gestational age.

Conclusion: Term neonates delivered by elective caesarean section are at increased risk for developing Respiratory distress compared vaginal delivery. The neonatal Respiratory distress decreased if elective caesarean delivery performed after 39 gestational weeks

Keywords: RD (Respiratory distress), ECS (elective caesarean delivery), TTN (transient tachypnea of the newborn), GA (gestational age), O2 (oxygen therapy), SVD (spontaneous vaginal delivary), NCU (Neonatal care unit).

\section{Introduction:}

Respiratory distress is one of common presentation in the newborn which occurs in up to $7 \%$ (1). a lot of studies done on RDS and bronchopulonary disease in preterm infants, $(2,3)$ but daily a significant number of term neonate are managed in NCU for their RD. $(4,5,6)$ $\mathrm{RD}$ in the neonate most commonly presents as one or all of the following physical signs: tachypnea ,grunting , nasal flaring, retraction and cyanosis. (7)

Causes RD in newborns: $(8,9,10)$

Common conditions: TTN, Pneumonia, RDS, Meconium aspiration syndrome (MAS), Pneumothorax , pulmonary hypertension ,congenital heart disease and Hypoxic ischaemic encephalopathy. Rae conditions: Pulmonary haemorrhage , Pleural effusion, Neuromuscular disorders, inborn error of metabolism, Diaphragmatic hernia, Tracheo oesophageal fistula, Choanal atresia, Cystic congenital adenomatoid malformation ,Lobar emphysema,Pulmonary hypoplasia. Aims of study to

*Children welfare teaching hospital, medical city yassealsadi@yahoo.com evaluate the effect of ECS timing on respiratory outcomes in term infants and To compare the risk of dveloping RD in association between ESC and SVD. Patients and Methods Aprospectively cohort study. All singleton term infants (who completed 37 to 41 gestational weeks) who were born by ECS and SVD at Baghdad Teaching Hospital/ medical city from 1st September 2015 to 31st January 2016 were evaluated for RD. The exclusion criteria included those women with the multiple gestations, had labour or attempted induction, had medical or obstetrical conditions such as (preeclampsia, eclampsia, diabetes mellitus, renal disease ,cardiac disease, placenta previa, placental abruption, still birth) that may increase the risk of neonatal illness, Infants with congenital malformations or infection including pneumonia or MAS also excluded due to the cause of $\mathrm{RD}$ in these cases unrelated to delayed transition from fetus to term neonate, the definition of ECS as a delivery occurred before the labour onset . (11) Indications for ECS included mother decision fetus mal presentation, repeated cesarean. (12) The information of the infants 
and mother included : maternal age, indication of ECS, gestational age, birth weight, gender, neonatal respiratory outcomes which included (TTN, RDS, pneumothorax) and also included others therapeutic measures which included :type of respiratory support required( $\mathrm{O} 2$, assisted ventilation), length of hospital stay, and neonatal death .History, examination and investigations as a complete blood count ,c reactive protein, blood culture and chest $\mathrm{x}$ ray were carried out in the NCU to find out various etiologies of RD. All neonate was followed until discharged from NCU.

\section{Statistical methods:}

The data were analysed using Statistical Package for Social Sciences (SPSS) version 20 .The Chi square was used to assess the association between the data.The continuous data were represented by mean and standard deviation. Student's T test and Analysis of variances (ANOVA) tests were used to compare mean values between study groups ,P - Value of less than 0.05 was used as significance.

\section{Result:}

Overall 4115 liveborn singletons were delivered at Baghdad teaching hospital- medical city, between 1st of September 2015 till 31st of January 2016, 2711 women with pregnancy of GA from 37 to 41 completed weeks, with uncomplicated pregnancy were identified who underwent ECS and SVD .women who underwent ECS were 1407 (51.9\%) and for SVD were $1304(48.1 \%)$. The GA at delivery was the important factor to determine the risk of $\mathrm{RD}$, which was significantly higher with younger GA $(p=0.05)$. The commonest indication for ECS was previous CS for both group, the rate was $99 \%$ for those with $\mathrm{RD}$ $(p=0.002)$, and one was malpresentation $(1 \%)$.The mean birth weight of infants born by ECS was significantly lower for those with RD which was 2.757 $(\mathrm{p}=0.04)$.Males delivered by ECS were more at risk to develop RD (58.4\%) than female (41.6\%).Table 1

Table 1: Demographic maternal and neonatal information and the characteristics of ESC singleton deliveries at term with or without RD.

\begin{tabular}{|c|c|c|c|}
\hline Variables & $\begin{array}{l}\text { No } \\
\text { respiratory } \\
\text { DISTRESS } \\
(\mathrm{N}=1299)\end{array}$ & $\begin{array}{l}\text { With } \\
\text { respiratory } \\
\text { DISTRESS } \\
(\mathrm{N}=108)\end{array}$ & $P$ value \\
\hline Maternal age & $32 \pm 4.8$ & $33 \pm 4.9$ & 0.8 \\
\hline Gestational age (weeks) & $38 \pm 0.6$ & $37 \pm 0.4$ & 0.05 \\
\hline birth weight $(\mathrm{g})$. & $2.815 \pm 0.343$ & $2.757 \pm 0.355$ & 0.04 \\
\hline \multicolumn{4}{|l|}{ Indication for ESC } \\
\hline Previous CS & $1160(89 \%)$ & $107(99 \%)$ & 0.002 \\
\hline Malpresentation & $130(10 \%)$ & $1(0.9 \%)$ & \\
\hline Maternal request & $9(0.7 \%)$ & $0(0)$ & \\
\hline \multirow{2}{*}{ gender } & $717(55.2 \%)$ & $63(58.4 \%)$ & 0.3 \\
\hline & $582(44.8)$ & $45(41.6 \%)$ & \\
\hline
\end{tabular}

the risk of $\mathrm{RD}$ in infants delivered by ECS significantly higher than those delivered by SVD (11 folds higher, Odd ratio (OR) 11.12 (5.61 to 22.04)), and p-value $<0.0001$.Adjustment for potential confounding variables (AOR) which was Adjusted for neonates birth weight, gender, requirement assisted ventilation, not change the estimated risk, Bivariate analyses were repeated for pregnancies with low risk, also resulted in high risk estimates of RD. AOR at 37 wks was 4.61(2.04 to 10.73), AOR at 38 wks was 16.89 (1.93 to 117.31$)$, AOR at 39 wks was 6.27 (1.01 to 28.97). The risk also increased at 39 and $40 \mathrm{wks}$.

Table 2: Odds ratios of neonatal RD delivered by ESC, according to GA at delivery.

\begin{tabular}{|c|c|c|c|c|c|c|}
\hline $\begin{array}{l}\text { Gestational } \\
\text { Age }\end{array}$ & & No. of deliveries & $\begin{array}{l}\text { Infants with RD } \\
\text { No. }(\%)\end{array}$ & OR $(95 \% \mathrm{CI})$ & AOR $(95 \% \mathrm{CI})$ & p-values \\
\hline \multirow[t]{2}{*}{$(370-37+6)$} & ECS & 603 & $\begin{array}{l}75 \\
(12.4)\end{array}$ & $\begin{array}{l}4.99 \\
(2.27 \text { to } 10.99)\end{array}$ & $\begin{array}{l}4.61 \\
(2.04 \text { to } 10.73)\end{array}$ & \multirow[t]{2}{*}{$0.0001 *$} \\
\hline & SVD & 253 & $7(2.8)$ & Reference & Reference & \\
\hline \multirow[t]{2}{*}{$(380-38+6)$} & ECS & 460 & $21(4.3)$ & $\begin{array}{l}17.73(2.37 \text { to } \\
132.71)\end{array}$ & $\begin{array}{l}16.89 \text { (1.93 to } \\
117.31)\end{array}$ & \multirow[t]{2}{*}{$0.005 *$} \\
\hline & SVD & 391 & $1(0.3)$ & Reference & Reference & \\
\hline \multirow[t]{2}{*}{$(390-39+6)$} & ECS & 209 & $8(3.8)$ & $\begin{array}{l}6.33(1.33 \text { to } \\
30.1)\end{array}$ & $\begin{array}{l}6.27(1.01 \text { to } \\
28.97)\end{array}$ & \multirow[t]{2}{*}{$0.02 *$} \\
\hline & SVD & 320 & $2(0.6)$ & Reference & Reference & \\
\hline \multirow[b]{2}{*}{$(40$ 0-40+6) } & ECS & 106 & $4(1.9)$ & - & - & - \\
\hline & SVD & 235 & $0(0)$ & - & - & - \\
\hline \multirow[b]{2}{*}{$(410-41+6)$} & ECS & 29 & $0(0)$ & - & - & \multirow[t]{2}{*}{-} \\
\hline & SVD & 105 & $0(0)$ & - & - & \\
\hline \multirow[t]{2}{*}{ Over all } & ECS & 1407 & $108(7.7)$ & $\begin{array}{l}11.12(5.61 \text { to } \\
22.04)\end{array}$ & $\begin{array}{l}8.55(4.96 \text { to } \\
14.52)\end{array}$ & \multirow[t]{2}{*}{$\begin{array}{l}<0.0001 \\
*\end{array}$} \\
\hline & SVD & 1304 & $10(0.7)$ & Reference & Reference & \\
\hline
\end{tabular}

$\mathrm{OR}=$ Odds ratio, $\mathrm{CI}=$ confidence interval, $\mathrm{AOR}=$ Adjusted odds ratio, *

Significant at 0.05 level 
According to GA at delivery the risk of $\mathrm{RD}$ was calculated to every week of pregnancy at the time of ECS. It was found that increasing the risk of RD in infants born by ECS with decreased GA from 37 weeks to 40 weeks, There was about four folds increased the risk for 37 weeks than 39 weeks ( $\mathrm{p}$ $<0.001$ ), and more than one fold (1.2) for 38 weeks than 39 weeks, and the risk of RD was nearly the same at 40 weeks of GA (3.8\%).

Table 3: The risk of neonatal RD, according to GA at delivery for ECS

\begin{tabular}{llllll}
\hline $\begin{array}{l}\text { Gestational } \\
\text { age }\end{array}$ & $\begin{array}{l}\text { Total } \\
(\mathrm{N}=1407)\end{array}$ & $\begin{array}{l}\text { Adverse } \\
\text { respiratory } \\
\text { events } \\
(\mathrm{N}=108)\end{array}$ & $\begin{array}{l}\mathrm{OR} \\
\mathrm{CI})\end{array}$ & $(95 \%$ & $\mathrm{p}$-value \\
\hline 370 & -603 & $75(12.4)$ & 3.57 & $<0.001^{*}$ \\
$37+6$ & & & $(1.697 .53)$ & \\
\hline
\end{tabular}

\begin{tabular}{llllll}
\hline $\begin{array}{l}380 \\
38+6\end{array}$ & - & 460 & $21(4.6)$ & $\begin{array}{l}1.2 \\
(0.522 .76)\end{array}$ & 0.501 \\
\hline $\begin{array}{l}390 \\
39+6\end{array}$ & -209 & $8(3.8)$ & $\begin{array}{l}1 \\
\text { (Reference) }\end{array}$ & - \\
\hline $\begin{array}{l}40 \\
40+6\end{array}$ & -106 & $4(3.8)$ & $\begin{array}{l}1 \\
(0.293 .35)\end{array}$ & 0.392 \\
\hline $\begin{array}{l}410 \\
41+6\end{array}$ & -29 & $0(0)$ & - & - \\
\hline
\end{tabular}

The rate of both TTN and RDS decreased as GA advanced in infants delivered by ECS but the relation was statistically not significant. Only one Pneumothorax developed at 37 weeks $(0.1 \%)$. The rate of requirement of respiratory support (oxygen supplement ,CPAP, MV) was significantly decreased with increased GA in infants delivered by ECS. Table 4 (B)

Table 4 (A,B): The relation between (type of respiratory support,diagnosis) \& GA in infants of ECS.

\begin{tabular}{|c|c|c|c|c|c|c|}
\hline \multirow{2}{*}{$\begin{array}{l}\text { A- } \\
\text { Diagnoses }\end{array}$} & \multicolumn{5}{|c|}{ Gestational age at delivery/weeks No(\%) } & \multirow[t]{2}{*}{ p-value } \\
\hline & $\begin{array}{l}370-37+6 \\
N=603\end{array}$ & $\begin{array}{l}380-38+6 \\
=460\end{array}$ & $\begin{array}{l}390-39+6 \\
\mathrm{~N}=209\end{array}$ & $\begin{array}{l}400-40+6 \\
N=106\end{array}$ & $\begin{array}{l}410-41+6 \\
N=29\end{array}$ & \\
\hline TTN & $59(9.7 \%)$ & $18(3.9 \%)$ & $7(3.3 \%)$ & $4(3.7 \%)$ & $0(0 \%)$ & 0.9 \\
\hline RDS & $15(2.4 \%)$ & $3(0.6 \%)$ & $1(0.4 \%)$ & $0(0 \%)$ & $0(0 \%)$ & \\
\hline Pneumothorax & $1(0.1 \%)$ & $0(0 \%)$ & $0(0 \%)$ & $0(0 \%)$ & $0(0 \%)$ & \\
\hline \multirow{2}{*}{$\begin{array}{l}\text { B- Respiratory } \\
\text { support }\end{array}$} & \multicolumn{5}{|c|}{ Gestational age at delivery/weeks No(\%) } & \multirow[t]{2}{*}{ p-value } \\
\hline & $\begin{array}{l}370-37+6 \\
N=603\end{array}$ & $\begin{array}{l}380-38+6 \\
=460\end{array}$ & $\begin{array}{l}390-39+6 \\
N=209\end{array}$ & $\begin{array}{l}400-40+6 \\
N=106\end{array}$ & $\begin{array}{l}410-41+6 \\
N=29\end{array}$ & \\
\hline $\begin{array}{l}\text { Oxygen } \\
\text { supplement }\end{array}$ & $19(3.1 \%)$ & $14(3 \%)$ & $6(2.8 \%)$ & $3(2.8 \%)$ & $0(0 \%)$ & \multirow[t]{3}{*}{0.004} \\
\hline CPAP & $46(7.6 \%)$ & $6(1.3 \%)$ & $2(0.9 \%)$ & $1(0.9 \%)$ & $0(0 \%)$ & \\
\hline MV & $10(1.6 \%)$ & $1(0.2 \%)$ & $0(0 \%)$ & $0(0 \%)$ & $0(0 \%)$ & \\
\hline
\end{tabular}

The mean of the length of hospital stay was increased with the decreased the gestational age, it was found $(6.17 \pm 4.29$ days $)$ at 37 weeks, decreased to $(4 \pm$ 1.41 days) at 40 weeks.

\section{Discussion:}

The frequency of delivery by ECS increased over the past 30 years, due to different causes of which changes of breech management, previous CS, medical illness of the mother, fetal cause, and 'maternal request (13), While results from studies on the importance of timing of ECS consistently showed increased risk of RD with decreasing GA such as Zanardo et al(14), Van de berg et al(15) Morrison et al (16). Most ECS were decided according to the clinician's opinion, a request from the parents and the availability of a theater, but there are major implications in the timing of ECS at term, since the incidence of RD could be halved for each additional week of pregnancy (17). Male delivered by ECS more to be at risk of RD, this is consistent with Dani c et al syudy (18), which show that male gender was a one of risk factor for RD; which explained by the hypothesis of later maturation of male fetuses who has poor ability to react to stress, inflammation response, and their blood pressure regulation $(18,19)$. Previous CS was the commonest indication for ECS in this study .The rate was $99 \%$ for those with RD, and one was malpresentation( $1 \%)$, these percentage was not similar to Kayoka et al study (20), who reported that previous $\mathrm{CS}$ as indication for ECS,represented $70 \%$ among infants with RD.(table 1) The mean birth weight of infants of ECS was significantly lower in infants with RD as in others studies, Kayoka etal (20) ,Tita et al (21), Alawkati et al (22). This study showed eleven folds risk increment of $\mathrm{RD}$ in neonates delivered by ECS compared to those were delivered vaginally. The RD risk after ECS in each week of gestation was compared with the risk after SVD, the risk was five folds at 37 weeks higher, seventeen folds at 38 weeks higher, six folds at 39 weeks higher, (Table 2 ), which was consistent by others studies ,Zanardo (23) , Van de berg (24), Morrison (25), Alawkati (22). Morrison et al (16) found that RD risk was increased 7 times by ECS, When stratified by gestational age,the risk decreased from 14 fold higher after 37 completed weeks of gestation to 3.5 fold after 
39 completed weeks of gestation. Zanardo et al (23) also show a three folds increased risk with ECS delivery, this risk was peaked at 37, 38 completed weeks of gestation. Al Awqati et al. (22) reported overall neonatal RD risk was significantly higher three to five folds in ECS delivery. In SVD there is a decrease secretion of liquid inside fetal lung with increased its absorption and the stimulation of surfactant release. $(25,26,27)$ This study also showed is consistent with other studies that stratified results by gestational age, as in Wilmink et al study (29), Tita et al. (21), Emily et al. (30). These Studies $(21,29,30)$ had similar aim of this study but they have different definition of ECS, exclusion criteria, choice of adverse outcomes, analysis by individual weeks of gestation and comparison with vaginal birth, making it difficult to directly compare this study with others. However, despite differing methodologies, the results of this study, which are similar with their results, when comparing the primary outcomes (which means in their study the RD that comprising all neonates admitted to NCU and receiving oxygen therapy or assisted ventilation (MV and/or CPAP). By Tita et al. (21), the rate of adverse respiratory outcomes at week 37 (AOR 2.5; 95\% CI 1.9- 3.3) and week 38 (AOR $1.7 ; 95 \%$ CI 1.4-2.1), two to three folds, compared to week 39. Also Wilmink et al. (29), reported a two to three folds increased risk of RD at week 37 (AOR 3.2; 95\% CI 2.5-4.2) and week 38 (AOR 1.7; 95\% CI 1.42.1), compared to week 39, including combined respiratory outcomes (RDS,TTN ,MV,CPAP, and neonatal death) which is similar to this study .Emily et al (30), reported early term (defined gestational age from week 37-38), was compared to full term (defined gestational age from week 39-41), (AOR 1.234.03), the risk increased two to four folds ,the RD comprising all 36 neonates admitted to NCU with a RD (which included RDS,TTN, pneumothorax), and receiving assisted ventilation with $\mathrm{MV}$ and/or CPAP, and neonatal death, which similar to this study. When the results were stratified by gestational age from 37 weeks to 40 weeks, the rate of both TTN, and RDS diminished for each week of gestation increased, the rate of TTN was from 59/603( 9.7\%) at 37 weeks to $7 / 209(3.3 \%)$ at 39 weeks, and $4 / 106(3.7 \%$ ) at 40 weeks, while RDS decreased from 15/603(2.4\% ) at 37 weeks to $1 / 209$ ( $0.4 \%$ ) at 39 weeks, and no RDS at 40 weeks.(table 4 A) This study also showed significantly increased risk of required assisted ventilation(CPAP, MV) with earlier gestational age in infants of ECS. The rate of requiring CPAP was 46/603( 7.6\%) at 37 weeks, 6/460 (1.3\%) at 38 weeks, 2/209, 1/106 respectively $(0.9 \%$ ) at 39 weeks and 40 weeks, while ten infants required MV were at 37 weeks , and one at 38 weeks , and no one required at 39 weeks and 40 weeks, (Table 4B), these findings were consistent with studies, such as Vande berg (24), Wilmink that an important factor in determining respiratory morbidity of the newborn who were delivered by ECS was the gestational age at time of delivery ; as there was a progressive increased rate of RD with each less week of gestation,(28) while no significant difference at 39, 40 weeks $(3.8 \%)$; at $37 \mathrm{wk}$ four folds $75 / 603(12.4 \%)$ higher, at 38 wk more than one fold $21 / 460(4.6 \%)$ higher ,(Table 3) this

(29),Emily (30). The length of the hospital stay was increased with decreased gestational age in infants of ECS this is consistent with the study that was done by Tita et al. (21) Six infants 6/108 (5.6\%) died of those delivered by ECS, who admitted to neonatal department, all of them were delivered at 37 weeks, no death recorded among those who were delivered by SVD.

\section{Conclusion:}

A term neonate delivered by elective caesarean section are at increased risk for developing $\mathrm{RD}$ compared vaginal delivery. Asignificant reduction ofl respiratory morbidities would be obtained if elective caesarean delivery were done after 39 compleated weeks of gestation.

\section{Authors' Contributions:}

Asmaa Ghanim Tahir :collecting of data through interview with families who's their newborns and mothers were involved in the samples,sharing and analysis of the result

Manal Behnam Baythoon :suggesting the problem and sharing with analysis and getting the ethical consents.

Ysir Ibrahim AL Saddi: discussing the result and writing the manuscript.

\section{References:}

1- Kumar A, Bhat B.Epidemiology of respiratory distress of newborns. Indian Journal of Pediatrics 1996;63:93-8.

2- Kotecha $S$, Allen J. Oxygen therapy for infants with chronic lung disease. Arch. Dis Child Fetal Neonatal Ed 2002;87:F11-4

3- Shaw NJ, Kotecha S. Management of infants with chronic lung disease of prematurity in the United Kingdom. Early Hum Dev 2005;81:165-70

4- Hibbard J, Wilkins I, Sun L, Gregory K, Haberman $S$, Hoffman $M$, et al. Respiratory morbidity in late preterm births. JAMA 2010;304:41925

5- Qandalji B. Full term neonatal admissions. Early Human Development Conference: 2nd Union of European Neonatal and Perinatal Societies, UENPS Congress .Academic Olympics Istanbul Turkey Conference Start 2010; 86(pp S133):S133

6- Qian Liling, LIU Cuiqing, Guo Yunxia, Jiang Yejun, Shiwen, et al., Current status of neonatal acute 
respiratory disorders: a one year prospective survey from a Chinese neonatal network. Chinese Medical Journal .2010;123:2769-75

7- Aly H. Respiratory disorders in the newborn: identification and diagnosis. Pediatr Rev. 2004;25:201-208

8- Schreiner RL, Bradburn NC. Newborns with acute respiratory distress: diagnosis . and management. Pediatr Rev. 1988;9:279-285

9- Abdel Latif ME, Oei J, Ward M, Wills EJ, Tobias V, Lui $K$.A respiratory distress diagnosis. Arch Dis Child Educ Pract Ed 2008;93:112-9

10- Bishop NB, Stankiewicz P, Steinhorn RH. Alveolar capillary dysplasia. .American Journal of Respiratory and Critical Care Medicine . 2011;184:172-9

11-Deluca R, Boulvain M, Irion O, Borner M, Pfisters $R E$. Incidence of early neonatal mortality and morbidity, after late preterm and term cesarean delivery.Pediatrics 2009; 123:e1064e1071.

12-American College of Obstetricians and Gynecologists. Committee opinion no.559: Cesarean delivery on maternal request. Obstet Gynecol 2013; 121: 904-907

13-Jackson NV, Irvine LM. The influence of maternal request on the elective caesarean section rate. J Obstet Gynaecol. 1998; / 18: 1159

14-Zanardo $V$, Simbi AK, Franzoi $M$, Solda $G$, Salvadori A, Trevisanuto D. Neonatal respiratory morbidity risk and mode of delivery at term: influence of timing of elective caesarean delivery; Acta Paediatr 2004; 93:643647

15-van den Berg A, van Elburg RM, van Geijn HP, Fetter WP. Neonatal respiratory morbidity following elective caesarean section in term infants: a 5year retrospective study and a review of the literature. Eur J Obstet Gynecol Reprod Biol 2001;98:913

16-Morrison JJ, Rennie JK, Milton PJ. Neonatal respiratory morbidity and mode of delivery at term: influence of timing of elective caesarean section. $\mathrm{Br} J$ Obstet Gynecol. 1995; 102 (2): 101106

17-Halliday HL.Elective delivery at term: implications for the neonate. Acta Paed 1999; 88: 1180-3 46

18-Dani C, Reali MF, Bertini G, Wiechmann L, Spagnolo A, Tangucci $M$, et al. Risk factors for the development of respiratory distress syndrome and transient tachypnoea in newborn infants. Italian Group of Neonatal Pneumology. EurRespir J 1999; 14:155-9
19-Kasap B, Duman N, Ozer E, et al. Transient tachypnea of the newborn: predictive factor for prolonged tachypnea Pediatr Int.2008;50:81-84

20-Kayoko Terada, Marie Ito, Sakae Kumasaka and Shunji Suzuki.Timing of Elective Cesarean Singleton Delivery and Neonatal Respiratory Outcomes at a Japanese Perinatal Center.J Nippon Med Sch 2014; 81 (4)

21-Tita AT, Landon MB, Spong CY et al. Timing of elective repeat cesarean delivery at term and neonatal outcomes. N Engl J Med 2009; 360: 111-120

22-Alawqati T.A, Kamal D.N, AlJuboury S.K, Salman W.A. Timing of elective repeated caesarean section: A risk factor for Acute neonatal respiratory morbidity ((hospital-based study)),IraqiJ.comm.Med., Apr.2012 ;2: 103106

23-Zanardo $V$, Simbi AK, Franzoi $M$, Solda $G$, Salvadori A, Trevisanuto D. Neonatal respiratory morbidity risk and mode of delivery at term: influence of timing of elective caesarean delivery; Acta Paediatr 2004; 93:643647

24-van den Berg A, van Elburg RM, van Geijn HP, Fetter WP. Neonatal respiratory morbidity following elective caesarean section in term infants: a 5year retrospective study and a review of the literature. Eur J Obstet Gynecol Reprod Biol 2001;98:913

25-Jost PA, Policard A. Contribution experimentale a L'etude du developpement prenatal du poumon chez le lapin. Arch D'Anatomie Microscopique. 1948;37:323332

26-Souza P, O’Brodovich H, Post M. Lung fluid restriction affects growth, but not .airway branching of embryonic rat lung. Int J Dev Biol. 1995;39:629-637

27-Elias N, O'Brodovich $H$. Clearance of fluid from airspaces of newborns and infants. NeoReviews. 2006;7:e88-e93 42

28-Kitterman JA, Ballard PL, Clements JA, et al. Tracheal fluid in fetal lambs: . spontaneous decrease prior to birth. J Appl Physiol. 1979;47:985-989

29-Wilmink FA, Hukkelhoven CW, Lunshof S. et al. Neonatal outcome following elective cesarean section beyond 37 weeks of gestation: a 7 year retrospective analysis of a national registry. Am J Obstet. Gynecol. 2010; 202: 250.e1-250.e8

30-Emily DOAN,1 Kristen GIBBONS2,3 and David TUDEHOPE1.The timing of elective caesarean deliveries and early neonatal outcomes in singleton infants born 37-41weeks' gestation. Australian and New Zealand Journal of Obstetrics and Gynaecology 2014; 54: 340-347 DOI: 10.1111/ajo. 